\title{
Analysis of Charge Transfer for in Situ Li Intercalated Carbon Nanotubes ${ }^{\perp}$
}

\author{
Kuldeep Rana, ${ }^{\dagger}$ Gokce Kucukayan-Dogu, ${ }^{\ddagger}$ H. Sener Sen, ${ }^{\S}$ Chris Boothroyd, ${ }^{\|}$Oguz Gulseren, ${ }^{\S}$ \\ and Erman Bengu* ${ }^{\dagger}$ \\ ${ }^{\dagger}$ Department of Chemistry, Bilkent University, 06800 Ankara, Turkey \\ ${ }^{\ddagger}$ Institute of Engineering and Science, Materials Science and Nanotechnology Graduate Program, Bilkent University, 06800 Ankara, \\ Turkey \\ ${ }^{\S}$ Department of Physics, Bilkent University, 06800 Ankara, Turkey \\ "Forschungszentrum Julich, D-52425 Julich, Germany
}

\section{Supporting Information}

ABSTRACT: Vertically aligned carbon nanotube (VA-CNT) arrays have been synthesized with lithium ( $\mathrm{Li}$ ) intercalation through an alcohol-catalyzed chemical vapor deposition technique by using a Li-containing catalyst. Scanning electron microscopy images display that synthesized carbon nanotubes (CNTs) are dense and vertically aligned. The effect of the Li-containing catalyst on VA-CNTs has been studied by using Raman spectroscopy, X-ray photoelectron spectroscopy (XPS), and electron energy loss spectroscopy (EELS). XPS results show the change in binding energy of $\mathrm{Li} 1 \mathrm{~s}$ and $\mathrm{C} 1 \mathrm{~s}$ peaks, which indicates that $\mathrm{Li}$ is inserted in VA-CNTs during growth. Analysis of Raman spectra reveals that the G-band profile of CNTs synthesized with the Li-containing catalyst is shifted, suggesting an electronic interaction between $\mathrm{Li}$ and neighboring $\mathrm{C}$ atoms of the CNTs. The EELS spectra of the $\mathrm{C} \mathrm{K}$ edge and Li K edge from CNTs also confirmed that $\mathrm{Li}$ is inserted into CNTs during synthesis. We have performed ab inito calculations based on density functional theory for a further understanding of the structural and electronic properties of Li intercalated CNTs, especially addressing the controversial charge-transfer state between $\mathrm{Li}$ and $\mathrm{C}$.

\section{INTRODUCTION}

Carbon-based materials are prime candidates for electrode applications in lithium $(\mathrm{Li})$-ion batteries due to their structural stability and high capacity. ${ }^{1-9}$ Improvements in the $\mathrm{Li}$ adsorption capacity of the carbon nanotube (CNT)-based anodes have been reported with the help of doping, functionalizing, defect engineering, and hybridizing CNTs with fullerenes. ${ }^{10}$ Further enhancements are also reported by ex situ doping of CNTs with $\mathrm{Li}^{6}$ and using vertically aligned carbon nanotube (VA-CNT) arrays as electrodes. ${ }^{11}$

Despite the volume of experimental and theoretical works on electronic and structural changes induced by the intercalation of $\mathrm{Li}$ in graphite ${ }^{12-16}$ and in $\mathrm{CNTs}^{5,17,18}$ charge transfer between $\mathrm{Li}$ and the hexagonal carbon network remains a subject of controversy. Results of some computational studies on intercalation of alkali metals in graphite indicate complete charge transfer, ${ }^{14}$ contrary to others suggesting a partial charge transfer. ${ }^{19-21}$ X-ray photoelectron spectroscopy (XPS) ${ }^{22,23}$ and electron energy loss spectroscopy (EELS) ${ }^{24}$ have been mainly used to probe the nature of the charge transfer experimentally and have given inconsistent results.

Recently, there were few reports of CNTs and carbon nanostructures grown on Li-containing compounds; ; $^{95,26}$ however, incorporation of $\mathrm{Li}$ to the carbon network has not been examined in detail. In this study, we have demonstrated in situ Li intercalation of CNTs during their synthesis. Scanning/ transmission electron microscopy (S/TEM), EELS, XPS, and Raman spectroscopy were used to confirm the insertion of $\mathrm{Li}$ in the CNT network. Following these results, we have also performed $a b$ initio density functional theory (DFT) calculations on various geometries to understand the energetically stable configurations for $\mathrm{Li}$ insertion and the resulting charge distribution. To address the existing controversy over charge transfer, we have employed orders of magnitude denser meshes than usual to achieve reliable convergence. To the best of our knowledge, this is the first attempt where in situ $\mathrm{Li}$ intercalation of VA-CNTs is successfully demonstrated, and in addition, both experimental and $a b$ initio analysis have been used for correlating the charge transfer.

Received: February 10, 2012

Revised: April 24, 2012

Published: April 30, 2012 


\section{EXPERIMENTAL METHODS}

Two types of catalyst solutions were prepared. The first was a Li-containing catalyst solution prepared by dissolving $\mathrm{Al}$ $\left(\mathrm{NO}_{3}\right)_{3} \cdot 9 \mathrm{H}_{2} \mathrm{O}, \mathrm{Co}\left(\mathrm{NO}_{3}\right)_{2} \cdot 6 \mathrm{H}_{2} \mathrm{O}$, and $\mathrm{LiNO}_{3}$ (molar ratio of $\mathrm{Al} / \mathrm{Co} / \mathrm{Li}$ is $1 / 1 / 1.4)$ in $10 \mathrm{~mL}$ of ethanol, and the second was with $\mathrm{Al}\left(\mathrm{NO}_{3}\right)_{3} \cdot 9 \mathrm{H}_{2} \mathrm{O}$ and $\mathrm{Co}\left(\mathrm{NO}_{3}\right)_{2} \cdot 6 \mathrm{H}_{2} \mathrm{O}$ (molar ratio of $\mathrm{Al}$ / $\mathrm{Co}$ is $1 / 1)$. These solutions were coated onto the oxidized $\mathrm{Si}(100)$ substrates. Next, the substrates were treated in a furnace by alcohol-catalyzed chemical vapor deposition (ACCVD), which has two steps: (a) reduction and (b) reaction where ethanol was introduced to facilitate CNT growth. ${ }^{27}$ A summary of the experiments is given in Table 1.

\section{Table 1. Summary of Experiments}

\begin{tabular}{cllc} 
experiment & \multicolumn{1}{c}{ catalyst } & \multicolumn{1}{c}{ ACCVD run } & after ACCVD \\
Set 1 & Li-containing Co & reduction + reaction & CNT \\
Set 2 & Li-containing Co & reduction & \\
Set 3 & Co & reduction + reaction & CNT \\
Set 4 & Co & reduction & \\
\hline
\end{tabular}

\section{RESULTS AND DISCUSSION}

Scanning electron microscopy (SEM) images of VA-CNTs from Set 3 and Set 1 are shown in Figure 1a,b. These crosssectional views show that CNTs are aligned perpendicular to the surface of the substrates. The morphology of individual CNTs grown with $\mathrm{Li}$ (Set 1) was further investigated by S/ TEM (Figure 1c). The length of the CNTs was measured to be $\sim 5 \mu \mathrm{m}$, and the diameters were between 10 and $20 \mathrm{~nm}$.

The EEL spectra of Li K and C K edges are shown in Figure $1 \mathrm{~d}$,e, obtained from the CNTs grown in Set 1, respectively. The $\mathrm{Li} \mathrm{K}$ edge is observed at $55.6 \mathrm{eV}$, which is shifted by $0.6-0.8 \mathrm{eV}$ with respect to the metallic $\mathrm{Li} \mathrm{K}$ edge, reported at $55^{28}$ and 54.8 $\mathrm{eV}^{12}$ This shift in the $\mathrm{Li} \mathrm{K}$ edge is expected due to charge transfer from the $\mathrm{Li}$ to the $\mathrm{C}$ atoms. Hightower et al. ${ }^{24}$ also reported a $0.2 \mathrm{eV}$ shift for bulk $\mathrm{LiC}_{6}$.

The $\mathrm{C} \mathrm{K}$ edge has a sharp edge just below the main absorption threshold (Figure 1e). This is characteristic of the excitation of electrons from the $\mathrm{C} 1 \mathrm{~s}$ orbital to states above the Fermi level, suggesting that graphite-like sheets are present in the sample. In our study, we observed that this edge is centered about $285.5 \mathrm{eV}\left(\pi^{*}\right)$, which corresponds to the unoccupied antibonding $\pi^{*}$ states of $\mathrm{sp}^{2}$-hybridized C. This edge is reported to be at $285 \mathrm{eV}$ for pure $\mathrm{CNTs}^{29}$ and at $285.5 \mathrm{eV}$ for CNTs intercalated by alkali metals. ${ }^{30,31}$ Hence, our measurements are in agreement with the earlier reports and confirm the presence of $\mathrm{Li}$ in CNTs.

High-resolution Raman spectra were also analyzed for Set 1 and Set 3 (Figure 1f). The $\mathrm{G}$ band ( $\mathrm{E}_{2 \mathrm{~g}}$ mode) corresponding to in-plane vibration of $\mathrm{C}$ atoms ${ }^{32,33}$ was observed at 1594 and $1582 \mathrm{~cm}^{-1}$ for CNTs grown in Set 1 and Set 3, respectively. However, the D band for both samples, which is attributed to disorder and defects in the CNTs, ${ }^{33}$ was observed at the same wavenumber of $1344 \mathrm{~cm}^{-1}$ and did not get affected by the presence of $\mathrm{Li}$. Several studies also reported a shift toward higher wavenumbers for the $\mathrm{G}$ band $\left(11 \mathrm{~cm}^{-1}\right.$ in this study); this is due to the insertion of the $\mathrm{Li}$ atom between the layers and charge transfer from $\mathrm{Li}$ to the $\mathrm{C}$ matrix. ${ }^{34,35}$

TEM and Raman spectra provide strong support for the presence of Li in the CNTs; nevertheless, an XPS analysis was conducted. XPS spectra for Li 1s and C 1s peaks are shown in
Figure 2, and the binding energies $\left(E_{\mathrm{B}}\right)$ of the peaks are tabulated in Table 2. To understand the chemical state of $\mathrm{Li}$, Set 2 and Set 4 samples were synthesized. An XPS spectrum from Set 4 is shown in Figure $2 \mathrm{a}$ and has a broad asymmetric peak centered on $59.5 \mathrm{eV}$ corresponding to Co $3 \mathrm{~d}^{36}$ In the XPS spectrum from Set 2, a second peak appears at $54.9 \mathrm{eV}$ corresponding to metallic $\mathrm{Li}^{37}$ (Figure $2 \mathrm{~b}$ ). This shows that the $\mathrm{Li}$ and $\mathrm{Co}$ on the substrates after the reduction step were metallic.

XPS analysis has been also carried on VA-CNTs synthesized in Set 1 and Set 3 to confirm the chemical state of Li. Figure 2c shows the Co $3 \mathrm{~d}$ peak centered at $59.5 \mathrm{eV}$ for Set 3. For Set 1 (Figure $2 \mathrm{~d}$ ), three peaks were found around $55 \mathrm{eV}$ (metallic $\mathrm{Li}$ ), $55.8 \mathrm{eV}$ (intercalated $\mathrm{Li}$ ), and $59.5 \mathrm{eV}$ (Co 3d). The $\mathrm{Li} \mathrm{1s}$ peak for the intercalated $\mathrm{Li}$ in the $\mathrm{LiC}_{6}$ compound was reported at $56 \mathrm{eV}$ with a shift toward higher $E_{\mathrm{B}}$ compared to metallic $\mathrm{Li}^{38}$ This shift is due to charge transfer from $\mathrm{Li}$ to the $\mathrm{C}$ matrix. ${ }^{38}$ In our study, when we compare the $E_{\mathrm{B}}$ of Li 1s for Set $1(55.8 \mathrm{eV})$ with Set $2(54.9 \mathrm{eV})$, there is a shift toward higher $E_{\mathrm{B}}$, which can be suggested as another evidence for $\mathrm{Li}$ intercalation during CNT growth (Set 1).

A detailed analysis of the $\mathrm{C} 1 \mathrm{~s}$ peak was also conducted to confirm $\mathrm{Li}$ intercalation. The shape of the $\mathrm{C} 1 \mathrm{~s}$ peak from Set 1 (Figure 2e) is different than that for the CNTs in Set 3 (Figure 2f). After deconvolution of the $C 1$ s peak from Set 3, the main peak (graphitic C) appears at $284.3 \mathrm{eV}$ (fwhm $0.7 \mathrm{eV}$ ) with a broad component at $285.5 \mathrm{eV}$ due to $\mathrm{C}-\mathrm{H}$ bonding ${ }^{39,40}$ (Figure 2e). The deconvolution of $\mathrm{C} 1 \mathrm{~s}$ peak from Set 1 results in multiple peaks; a main component at $284.3 \mathrm{eV}$ and a broader one at $285 \mathrm{eV}$ (Figure 2f). The peak at $285 \mathrm{eV}$ corresponds to the Li intercalated CNTs and shifted toward the higher $E_{\mathrm{B}}$ side compared with the component at $284.3 \mathrm{eV}$, which is the $\mathrm{BE}$ of the $\mathrm{C} 1 \mathrm{~s}$ of CNTs without Li. Generally, C 1s peaks between 285 and $285.2 \mathrm{eV}$ are attributed to $\mathrm{Li}$ intercalated $\mathrm{C}$, such as $\mathrm{LiC}_{6}$ and $\mathrm{LiC}_{2}{ }^{41}$ Besides, the broader appearance of this peak with respect to that for graphitic $\mathrm{C}(284.3 \mathrm{eV})$ was considered to be due to charge redistribution on $\mathrm{C}$ induced by $\mathrm{Li}^{39,42,43}$ XPS analyses results for the ex situ intercalation attempt are provided in the Supporting Information.

We have also performed first-principles plane-wave calculations ${ }^{44-46}$ within DFT by the projector-augmented wave (PAW) potentials. ${ }^{47,48}$ Both the local density approximation $(\mathrm{LDA})^{49}$ and the generalized gradient approximation (GGA) ${ }^{50}$ were employed for the description of the exchange-correlation potential. We used various configurations based on a bilayer graphene system with $\mathrm{AA}$ (8 initial configurations) and $\mathrm{AB}$ (12 initial configurations) stacking to understand the $\mathrm{Li}$ interaction. The large supercell is set as a $6 \times 6$ bilayer graphene in plane with around $15 \AA$ of vacuum in the perpendicular direction. Accordingly, we have used a $7 \times 7 \times 1$ Monkhorst-Pack ${ }^{51} k$ point mesh for sampling the Brillouin zone. All edge $\mathrm{C}$ atoms furthest away from the $\mathrm{Li}$ atom are frozen in order to keep the $3.34 \AA$ distance between the graphene layers, but allowing the relaxation of atoms in the vicinity of $\mathrm{Li}$. All $\mathrm{Li} /$ bilayer graphene configurations were optimized, and the corresponding binding energies of the $\mathrm{Li}$ were calculated to understand how $\mathrm{Li}$ binds with CNTs. Even though the resulting binding energies were different, their order and corresponding physical picture were similar regardless of the stacking and functionals used. Hence, we only discussed the results from AA stacking with the LDA potential throughout. Furthermore, for resolving the controversial discussion for charge transfer, we have investigated the charge densities of the systems from the converged 

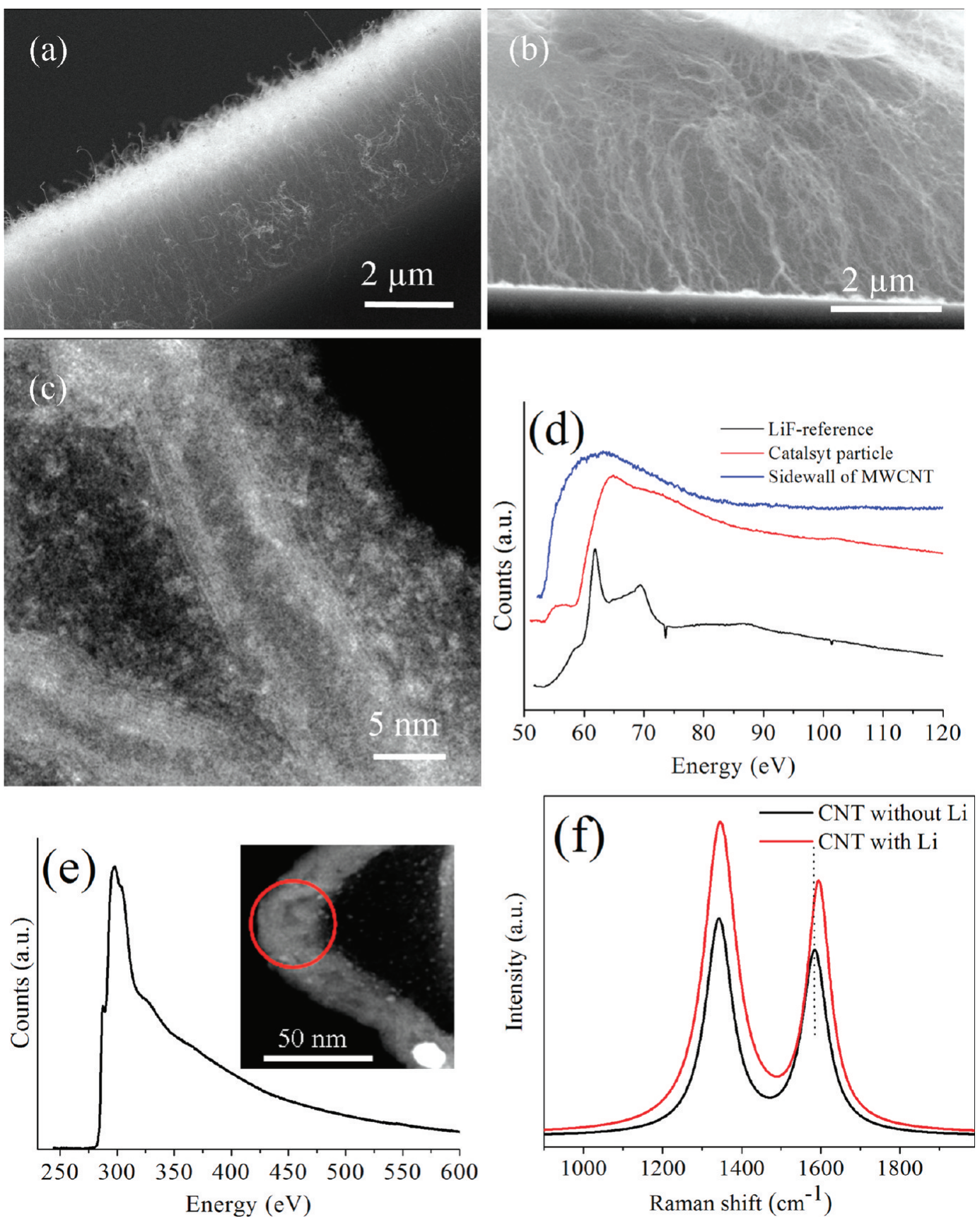

Figure 1. Cross-sectional SEM images of VA-CNTs from (a) Set 3 and (b) Set 1. (c) S/TEM image of a CNT from Set 1. EEL spectra of Set 1 for (d) Li K edge and (e) C K edge (inset shows where the spectrum is taken from). (f) Raman spectra from Set 1 and Set 3.

calculations using Bader analysis. ${ }^{52,53}$ All the results can be described in three groups as follows:

Adsorption. We have three possible adsorption sites; top (on top of a $\mathrm{C}$ atom), hollow site (above the center of a hexagon), and the bridge site (above the bond between two C's) as labeled by 1, 2, and 3 in Figure 3a, respectively. After geometry relaxation, we observed that the $\mathrm{Li}$ ended up $\sim 2.2 \AA$ away from the nearest $\mathrm{C}$ and makes a bond accordingly. Of these adsorption geometries, the most stable site energetically (highest binding energy) is adsorption above the center of a hexagon with the binding energy of $2.29 \mathrm{eV}$, while the other sites have binding energies of around $1.9 \mathrm{eV}$.

Substitution. We tried $\mathrm{Li}$ substitution geometries by removing one $\mathrm{C}$ and substituting it with $\mathrm{Li}$. Understandably, a very tight geometry is present in terms of bond lengths; that is, $\mathrm{C}-\mathrm{C}$ is $1.42 \AA$, whereas the $\mathrm{Li}-\mathrm{C}$ bond distance is around $2.2 \AA$. Because of this, we have also considered a double $\mathrm{C}$ vacancy on graphene. Substitutional $\mathrm{Li}$ could then be introduced as there is more space available. Nevertheless, in both of the cases, the planar geometry is stretched to accommodate the Li. The resulting distortion of the planar structure of graphene is relaxed by $\mathrm{Li}$ wandering in between the graphene layers. There, $\mathrm{Li}$ positions such that it optimizes the $\mathrm{Li}-\mathrm{C}$ length to around $\sim 2.2 \AA$ in the defective graphene. The binding energy with respect to the corresponding defective graphene layer is 3.54 and $3.29 \mathrm{eV}$ for single and double vacancy cases, respectively. 

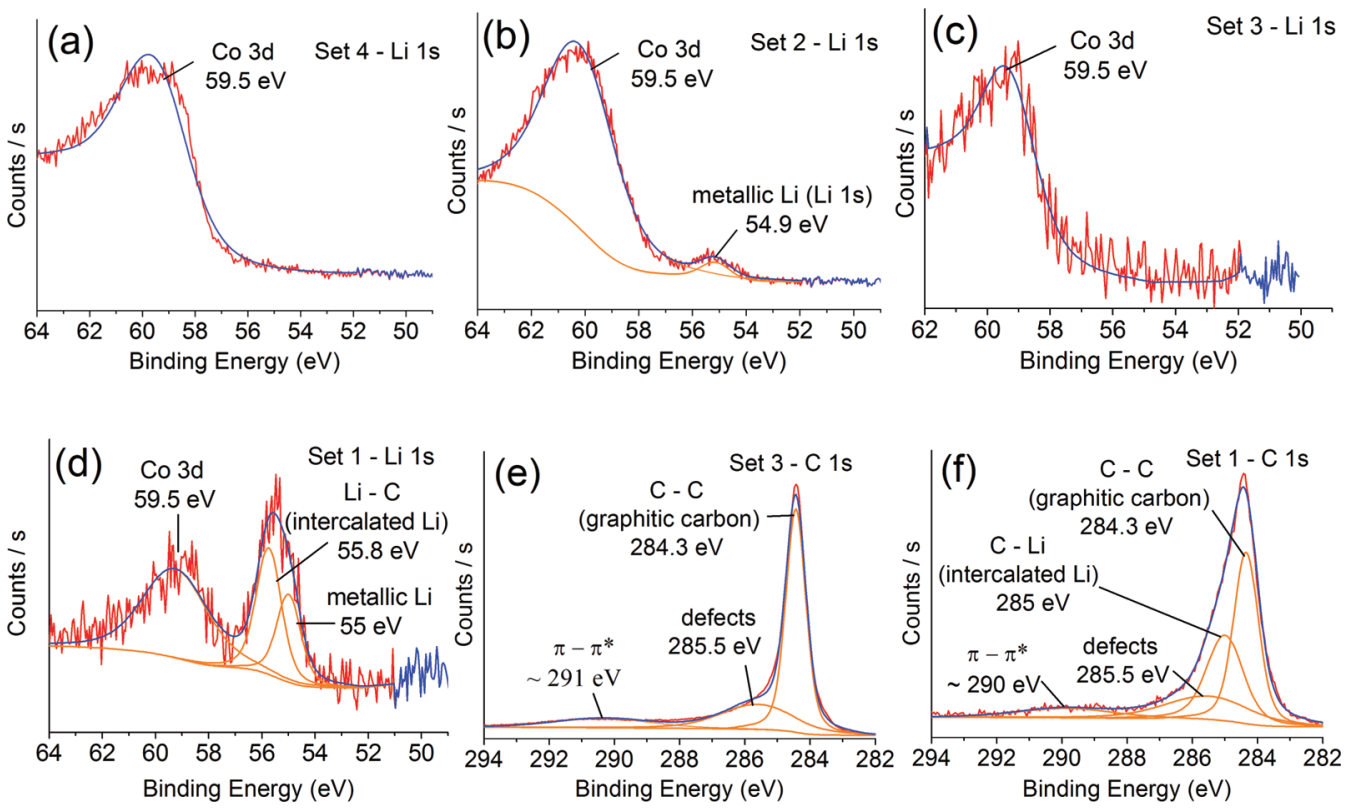

Figure 2. Li 1s XPS spectra of (a) Set 4, (b) Set 2, (c) Set 3, and (d) Set 1. C 1s XPS spectra of (e) Set 3 and (f) Set 1.

Table 2. $E_{\mathrm{B}}$ Position and fwhm for C 1s and Li 1s XPS Peaks

\begin{tabular}{ccc} 
samples & $E_{\mathrm{B}} \mathrm{Li} 1 \mathrm{~s}(\mathrm{eV})$ & $E_{\mathrm{B}} \mathrm{C} 1 \mathrm{~s}(\mathrm{eV})$ \\
Set 1 & 55.8 & $284.3(0.9) 285.0(1.9)$ \\
Set 2 & 54.9 & \\
Set 3 & & $284.3(0.7) 285.5(2.8)$ \\
\hline
\end{tabular}

Intercalation. We have checked possible different Li sites between the two graphene layers. As described earlier, Li tries to optimize the Li-C length to $\sim 2.2 \AA$; hence, it prefers to sit on a hollow site where there is more room for an interstitial

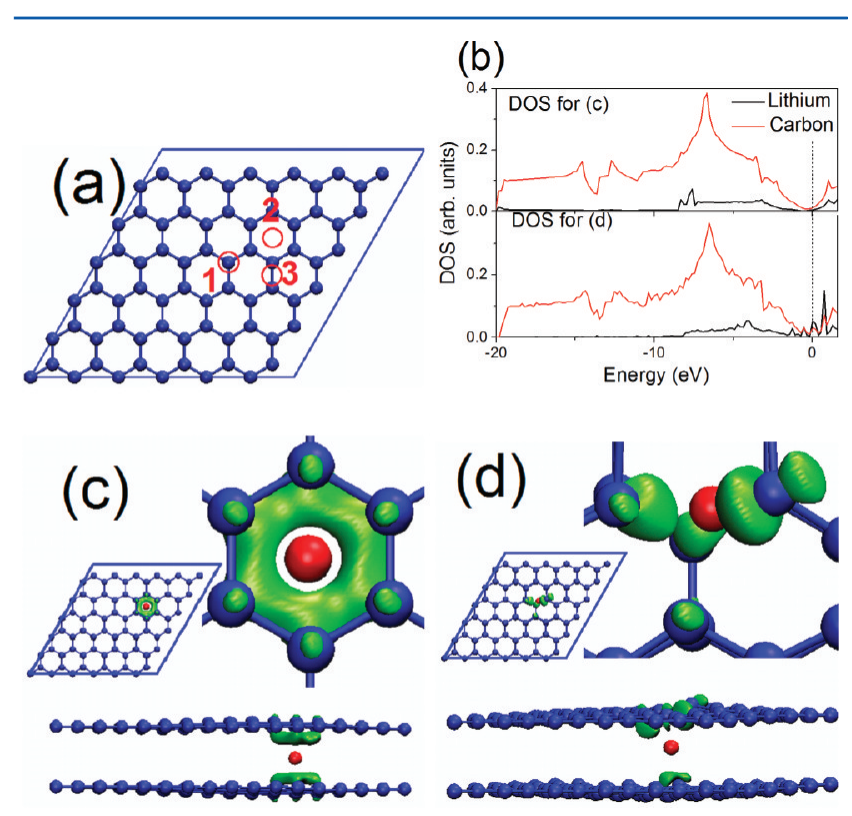

Figure 3. (a) Possible Li adsorption sites; top (1), hollow (2), and bridge (3) for a $6 \times 6$ unit cell. (b) PDOS for Li intercalated cases shown in (c) and (d). Dotted line indicates the Fermi level. Top and side views of the optimized geometry and the charge density of (c) $\mathrm{Li}$ intercalated bilayer graphene and $(\mathrm{d})$ a similar system, but starting from $\mathrm{Li}$ substitution to a $\mathrm{C}$ site on top layer. atom. The binding energy is $\sim 3.01 \mathrm{eV}$ in these cases. Besides, the projected density of states (PDOS) for these cases is shown in Figure $3 b$.

Energy minimization calculations resulted in eight different final adsorption configurations, and the binding energies, $\mathrm{Li}-\mathrm{C}$ bond distances, and total charge transfer from $\mathrm{Li}$ to the carbon network are listed in Table 3. LDA and GGA calculations show

Table 3. Binding Energies, $\mathrm{Li}-\mathrm{C}$ Bond Distances, and Total Charge Transfer from $\mathrm{Li}$ to $\mathrm{C}$ Network for Li-Doped AA Stacking Bilayer Resulted from LDA Calculations

\begin{tabular}{|c|c|c|c|}
\hline $\begin{array}{l}\text { adsorption } \\
\text { geometry }\end{array}$ & $\begin{array}{c}\text { binding } \\
\text { energy } \\
(\mathrm{eV})^{a}\end{array}$ & $\begin{array}{l}\mathrm{Li}-\mathrm{C} \text { bond } \\
\text { distance }(\AA)\end{array}$ & $\begin{array}{l}\text { total charge transferred } \\
\text { to } C \text { atoms }(\mathrm{e})\end{array}$ \\
\hline outer top & 1.93 & 1.99 & 0.9 \\
\hline outer bridge & 1.96 & 2.08 & 0.9 \\
\hline outer hollow & 2.29 & 2.21 & 0.88 \\
\hline mid top & 2.6 & 2.01 & 0.84 \\
\hline mid bridge & 2.63 & 2.09 & 0.84 \\
\hline mid hollow & 3.01 & 2.3 & 0.85 \\
\hline $\begin{array}{l}\text { substituted: single } \\
\text { C vacancy }\end{array}$ & 3.54 & 2.27 & 0.84 \\
\hline $\begin{array}{l}\text { substituted: double } \\
\text { C vacancy }\end{array}$ & 3.29 & 2.12 & 0.86 \\
\hline \multicolumn{4}{|c|}{$\begin{array}{l}{ }^{a} E_{\mathrm{binding}}=E_{\mathrm{total}}-\left(E_{\mathrm{bi}-g r a p h e n e}+n_{\mathrm{Li}} \times \mu_{\mathrm{Li}}\right) \cdot E_{\text {total }}: \text { total energy of the } \\
\text { relaxed composite system. } E_{\mathrm{bi} \text {-graphene }} \text { : energy of graphitic system (i.e. } \\
\text { bilayer graphene or bilayer graphene with vacancies). } n_{\mathrm{Li}}: \text { number of } \mathrm{L} \\
\text { atoms. } \mu_{\mathrm{Li}} \text { : chemical potential of a single } \mathrm{Li} \text { atom. }\end{array}$} \\
\hline
\end{tabular}

that it is energetically favorable for a $\mathrm{Li}$ atom to go in between the layers. The most stable case labeled as mid hollow is shown in Figure 3c. In this configuration, the $\mathrm{Li}$ atom tends to stay in the middle of the hexagons of two layers $(\mathrm{Li}-\mathrm{C}$ bond length $~$ $2.3 \AA$ ). However, as shown in Table 3, the binding energies for the intercalated $\mathrm{Li}$ starting from substituted $\mathrm{Li}$ (Figure $3 \mathrm{~d}$ ) are larger, since these were calculated with respect to the defective graphene bilayer system.

The last column of Table 3 shows the charge transferred from $\mathrm{Li}$ to the graphitic system, which is calculated using the Bader analysis. ${ }^{52,53}$ It is essential to calculate this charge transfer 
accurately in order to address the controversial results in the literature. Note that it is easy to associate the charge with the specific atom if the computational method is based on the local basis set, but generally, this approach is less accurate. On the other hand, one can systematically control the accuracy within the calculation using the plane-wave basis set, which requires the definition of a volume around the atom, including all the charge associated with it, a nontrivial task. For example, we used Bader analyses of a simple graphene layer as a benchmark: while the charge on the carbon atoms for a $1 \times 1$ unit cell was found to be 4.00 e, it fluctuated between 3.99 and 4.01 e for a 6 $\times 6$ unit cell. Another approach for calculating the charge of each atom from PDOS suffers from similar issues as well. Furthermore, in order to describe the charge transfer, the difference of charges before and after $\mathrm{Li}$ intercalation, one has to describe the charge around each atom very accurately. In this regard, we have examined all of the computational parameters in detail using the graphene and $\mathrm{LiC}_{6}$ systems. For instance, we have used as much as 10 times denser grids than the ones commonly used for accurate calculations in the literature for charge density calculations. Our final results clearly show that almost 0.86 electrons from the $\mathrm{Li}$ atom are transferred to neighboring $\mathrm{C}$ atoms, leaving a positively charged $\mathrm{Li}$ core behind. In Figure $3 c, d$, the transferred charge is displayed by presenting the difference charge density, calculated by subtracting the charge densities of the graphitic system and the $\mathrm{Li}$ atom from the charge density of the intercalated system. For the perfect intercalated case, it can be depicted that all atoms in the graphitic hexagons share the incoming electron from the $\mathrm{Li}$, as shown in Figure 3c. The extra charge is distributed symmetrically, and this electron tends to accommodate in the form of the $\mathrm{p}_{z}$ orbital of $\mathrm{C}$ atoms. For the defective intercalated cases, the extra charge is accommodated more around the missing $\mathrm{C}$ atoms to compensate for the dangling bonds (Figure 3d).

\section{CONCLUSIONS}

In this study, we have successfully intercalated $\mathrm{Li}$ into VACNTs during growth. The XPS and EELS spectra show the presence of $\mathrm{Li}$. The insertion of $\mathrm{Li}$ in VA-CNTs was confirmed by investigating the XPS spectra through the change in $E_{\mathrm{B}}$ for $\mathrm{Li} 1 \mathrm{~s}$ and $\mathrm{C}$ 1s. The charge transfer to the $\mathrm{C}$ lattice is another indication for $\mathrm{Li}$ in between graphitic layers, and this is also demonstrated by the upshift in the G band in Raman spectra. We have also performed first-principles calculations showing $\mathrm{Li}$ atoms having a strong tendency for intercalation. Our calculations revealed a transfer of almost one electron $(0.86$ e) from $\mathrm{Li}$ to the neighboring $\mathrm{C}$ network, in good agreement with the experimental results. Our study shows that pre-doping of CNTs with Li during growth is possible, which will be an efficient anode material in lithium-ion batteries, improving battery performance by reducing capacity loss in the first cycle and rate capability.

\section{ASSOCIATED CONTENT}

\section{S Supporting Information}

XPS spectra of additional experiments. This material is available free of charge via the Internet at http://pubs.acs.org.

\section{AUTHOR INFORMATION}

\section{Corresponding Author}

*Phone: +90 31229021 53. Fax: +90 31226640 68. E-mail: bengu@fen.bilkent.edu.tr.

\section{Author Contributions}

${ }^{\perp}$ The manuscript was written through contributions from all authors. All authors have given approval for the final version of the manuscript.

\section{Notes}

The authors declare no competing financial interest.

\section{ACKNOWLEDGMENTS}

We thank Dr. Li Kun at KAUST for the use of TEM facilities and the Scientific and Technological Research Council of Turkey (Tubitak) for financial support.

\section{REFERENCES}

(1) Basu, S. Rechargeable battery. U.S. Patent 4,304,825, December 8, 1981.

(2) Meunier, V.; Kephart, J.; Roland, C.; Bernholc, J. Phys. Rev. Lett. 2002, 88, 0755061-0755064.

(3) Che, B.; Lakshmi, B.; Fisher, E. R; Martin, C. R. Nature 1998, 393, 346-349.

(4) Liu, Y.; Zheng, H.; Liu, X. H.; Huang, S.; Zhu, T.; Wang, J.; Kushima, A.; Hudak, N. S.; Huang, X.; Zhang, S.; Mao, S. X.; Qian, X.; Li, J.; Huang, J. Y. ACS Nano 2011, 5, 7245-7253.

(5) Shimoda, H.; Gao, B.; Tang, X. P.; Kleinhammes, A.; Fleming, L.; Wu, Y.; Zhou, O. Phys. Rev. Lett. 2001, 88, 0155021-0155024.

(6) Yang, Z. H.; Wu, H. Chem. Phys. Lett. 2001, 343, 235-240.

(7) Maurin, G.; Henn, F.; Simon, B.; Colomer, J.-F.; Nagy, J. B. Nano Lett. 2001, 1, 75-79.

(8) Lee, Y. T.; Yoon, C. S.; Sun, Y. K. J. Power Sources 2005, 139, 230-234.

(9) Rana, K.; Sil, A.; Ray, S. Mater. Chem. Phys. 2010, 120, 484-489.

(10) Okada, S.; Saito, S.; Oshiyama, A. Phys. Rev. Lett. 2001, 86, 3835-3838.

(11) Welna, D. T.; Qu, L.; Taylor, B. E.; Dai, L.; Durstock, M. F. J. Power Sources 2011, 196, 1455-1460.

(12) Wang, F.; Graetz, J.; Moreno, M. S.; Ma, C.; Wu, L.; Volkov, V.; Zhu, Y. ACS Nano 2011, 5, 1190-1197.

(13) Kganyago, K. R.; Ngoepe, P. E. Phys. Rev. B 2003, 68, 205111120511116.

(14) Holzwarth, N. A. W.; Louie, S. G.; Rabii, S. Phys. Rev. B 1983, $28,1013-1025$.

(15) Hartwigsen, C.; Witschel, W.; Spohr, E. Phys. Rev. B 1997, 55, 4953-4959.

(16) Khantha, M.; Cordero, N. A.; Molina, L. M.; Alonso, J. A.; Girifalco, L. A. Phys. Rev. B 2004, 70, 1254221-1254227.

(17) Durgun, E.; Dag, S.; Bagci, V. M. K.; Gulseren, O.; Yildirim, T.; Ciraci, S. Phys. Rev. B 2003, 67, 2014011-2014014.

(18) Nishidate, K.; Hasegawa, M. Phys. Rev. B 2005, 71, 24541812454186.

(19) Benedek, R.; Smith, A. P.; Yang, L. H. Phys. Rev. B 1994, 49, $7786-7789$.

(20) Rytkonen, K.; Akola, J.; Manninen, M. Phys. Rev. B 2007, 75, 0754011-0754019.

(21) Chan, T. J.; Neaton, B.; Cohen, M. L. Phys. Rev. B 2008, 77, 235430-23543012.

(22) Mansour, A.; Schnatterly, S. E.; Ritsko, J. J. Phys. Rev. Lett. 1987, $58,614-617$.

(23) Balasubramanian, M.; Johnson, C. S.; Cross, J. O.; Seidler, G. T.; Fister, T. T.; Stern, E. A.; Hamner, C. S.; Mariager, O. Appl. Phys. Lett. 2007, 91, 031904-031907.

(24) Hightower, A.; Ahn, C. C.; Fultz, B.; Rez, P. Appl. Phys. Lett. 2000, 77, 238-240.

(25) Rana, K.; Sil, A.; Ray, S. Mater. Res. Bull. 2009, 44, 2155-2159. 
(26) Rana, K.; Sil, A.; Ray, S. Adv. Mater. Res. 2009, 67, 197-202.

(27) Baykal, B.; Ibrahimova, V.; Er, G.; Bengu, E.; Tuncel, D. Chem. Commun. 2010, 46, 6762-6764.

(28) Liu, D.-R.; Williams, D. B. Philos. Mag. 1986, 53, L123-L128.

(29) Xu, Y. J.; Liu, X.; Cui, G.; Zhu, B.; Weinberg, G.; Schlogl, R.; Maier, J.; Su, D. S. ChemSusChem 2010, 3, 343-349.

(30) Liu, X.; Pichler, T.; Knupfer, M.; Fink, J. Phys. Rev. B 2003, 67, $125403-125411$.

(31) Cupolillo, A.; Giallombardo, C.; Papagno, L. Surf. Sci. 2007, 601, $2828-2831$.

(32) Nemanich, R. J.; Solin, S. A.; Guerard, D. Phys. Rev. B 1977, 16, 2965-2972.

(33) Eklund, P. C.; Holden, J. M.; Jishi, R. A. Carbon 1995, 33, 959972.

(34) Bendiab, N.; Anglaret, E.; Bantignies, J.-L.; Zahab, A.; Sauvajol, J. L.; Petit, P.; Mathis, C.; Lefrant, S. Phys. Rev. B 2001, 64, 245424245430.

(35) Claye, A. S.; Nemes, N. M.; Janossy, A.; Fischer, J. E. Phys. Rev. B 2000, 62, 4845-4848.

(36) Strydom, A.; Strydom, H. J. Inorg. Chim. Acta 1989, 159, 191195.

(37) Baer, Y. P.; Citrin, H.; Wertheim, G. K. Phys. Rev. Lett. 1976, 37, $49-52$.

(38) Imanishi, N.; Ohashi, S.; Ichikawa, T.; Takeda, Y.; Yamamoto, O.; Kanno, R. J. Power Sources 1992, 39, 185-191.

(39) Kanamura, K.; Shiraishi, S.; Takezawa, H.; Takehara, Z. Chem. Mater. 1997, 9, 1797-1804.

(40) Buqa, H.; Blyth, R. I. R.; Golob, P.; Evers, B.; Schneider, I.; Alvarez, M. V. S.; Hofer, F.; Netzer, F. P.; Ramsey, M. G.; Winter, M.; Besenhard, J. O. Ionics 2000, 6, 172-179.

(41) Momose, H.; Honbo, H.; Takeuchi, S.; Nishimura, K.; Horita, T.; Muranaka, Y.; Kozono, Y.; Miayadera, H. J. Power Sources 1997, 68, 208-211.

(42) Wertheim, G. K.; Van Attekum, P. T. Th. M.; Basu, S. Solid State Commun. 1980, 33, 1127-1130.

(43) Mordkovich, V. Z. Synth. Met. 1996, 80, 243-247.

(44) Kresse, G.; Hafner, J. Phys. Rev. B 1993, 47, 558-561.

(45) Kresse, G.; Furthmüller, J. Comput. Mater. Sci. 1996, 6, 15-50.

(46) Kresse, G.; Furthmüller, J. Phys. Rev. B 1996, 54, 11169-11186.

(47) Blöchl, P. E. Phys. Rev. B 1994, 50, 17953-17979.

(48) Kresse, G.; Joubert, D. Phys. Rev. B 1999, 59, 1758-1775.

(49) Perdew, J. P.; Zunger, A. Phys. Rev. B 1981, 23, 5048-5079.

(50) Perdew, J. P.; Chevary, J. A.; Vosko, S. H.; Jackson, K. A.; Pederson, M. R.; Singh, D. J.; Fiolhais, C. Phys. Rev. B 1992, 46, 66716687.

(51) Monkhorst, H. J.; Pack, J. D. Phys. Rev. B 1976, 13, 5188-5192.

(52) Henkelman, G.; Arnaldsson, A.; Jonsson, H. Comput. Mater. Sci. 2006, 36, 354-360.

(53) Sanville, E.; Kenny, S. D.; Smith, R.; Henkelman, G. J. Comput. Chem. 2007, 28, 899-908. 